\title{
Luaran persalinan gemeli di RSUP Prof. Dr. R. D Kandou Periode 1 Januari 2014 - 31 Desember 2015
}

\author{
${ }^{1}$ Yoel B. Parlindungan \\ ${ }^{2}$ Freddy W. Wagey \\ ${ }^{2}$ Maya Mewengkang
}

\author{
${ }^{1}$ Kandidat Skripsi Fakultas Kedokteran Universitas Sam Ratulangi Manado \\ ${ }^{2}$ Bagian Obstetri-Ginekologi Fakultas Kedokteran Universitas Sam Ratulangi Manado \\ Email: nehemia.nybps@gmail.com
}

\begin{abstract}
Multiple pregnancies are pregnancy more than one fetuses. Multiple pregnancies increase seventy percent lately and effected on mortality and morbidity of maternal also fetal. This research is retrospective descriptive study with the purpose is outcome of twins' delivery in RSUP Prof. DR. R. D Kandou from January $1^{\text {st }} 2014$ until December $31^{\text {st }} 2015$. The result of this research show 60 events of twins' labor from 5038 labors $(0.012 \%)$, most founded on mother age $21-25$ years old with primiparas. The twins' outcome shows the most presentations are cephalic-cephalic with vaginal delivery method. The most duration of gestation is $34-37$ weeks shows prematurity is high. Female infants dominated. Birthweight show most $2000-2499 \mathrm{~g}$ on first infants and $2500-2999 \mathrm{~g}$ on second infants with 6-8 score of apgar.
\end{abstract}

Keywords: twins' delivery outcome, number of incidence.

\begin{abstract}
Abstrak: Kehamilan multijanin adalah kehamilan dengan jumlah janin lebih dari satu. Kehamilan kembar meningkat tujuh puluh persen saat ini dan meningkatkan angka mortalitas maupun morbiditas baik maternal maupun fetal. Penelitian ini menggunakan metode retrospektif deskriptif dengan tujuan untuk melihat luaran persalinan gemeli di RSUP Prof. DR. R. D Kandou periode 1 Januari 2014 - 31 Desember 2015. Hasil pengumpulan data dan penelitian menunjukan terdapat 60 kejadian persalinan gemeli dari 5038 persalinan $(0.012 \%)$, paling banyak ditemukan pada ibu usia 21 - 25 tahun dengan primipara. Luaran bayi ditemukan presentasi bayi paling banyak adalah kepala-kepala, dengan metode persalinan spontan pervaginam. Usia kehamilan terbanyak adalah $34-37$ minggu yang menunjukan tingginya prematuritas. Bayi perempuan mendominasi. Berat lahir terbanyak adalah 2000 - 2499 g pada bayi 1 dan 2500 - 2999 g pada bayi 2 dengan apgar skor terbanyak 6-8.
\end{abstract}

Kata kunci: luaran persalinan kembar, angka kejadian.

Kehamilan kembar dapat berasal dari dua sel telur yang dibuahi (kembar dizigotik/non-identik), maupun dapat berasal dari sebuah sel telur yang setelah dibuahi mengalami pembelahan menjadi dua bagian yang masing-masing berkembang menjadi mudigah (kembar monozigotik/identik). ${ }^{1}$ Jumlah kelahiran kembar di seluruh dunia saat ini meningkat
70\% dibanding rentang waktu 1980-2004 yang diperkirakan dikarenakan usia ibu yang meningkat dan pengobatan kesuburan. $^{2}$ Di kota Manado, Indonesia, khususnya di RSUP Prof. Dr. R. D. Kandou, pada tahun 2010-2011 angka kelahiran kembar sebanyak 45 kelahiran, dan pada tahun 2012-2013 terdapat 97 kelahiran kembar terjadi. ${ }^{3,4}$ 
Tdrdapat banyak faktor yang dapat meningkatkan kehamilan kembar, antara lain semakin seringnya penggunaan teknologi bantu reproduksi, herediter, tingginya usia ibu saat konsepsi dan tingginya jumlah paritas ibu. ${ }^{2}$

Kehamilan kembar meningkatkan angka morbiditas dan mortalitas baik maternal maupun fetal/neonatal. ${ }^{1}$ Neonatus kembar cenderung lahir dengan kurang bulan (prematur), mengakibatkan ancaman kecacatan permanen meningkat pada neonatus-neonatus kembar dan berat badan lahir rendah serta kecenderungan Apgar skor yang lebih rendah pada bayi kedua. ${ }^{5}$

Semua kombinasi posisi janin dapat terjadi pada kehamilan multijanin yang tersering adalah sefalik-sefalik, sefaliksungsang, dan sefalik-lintang. ${ }^{5}$ metode persalinan dari masing-masing kombinasi presentasi beragam: sefalik-sefalik spontan lebih baik, sefalik-nonsefalik sectio caesarea menunjukkan penurunan mortalitas akibat afiksia, sungsangsungsang sectio caesarea lebih baik. ${ }^{6-8}$ Persalinan pervaginam memberikan luaran yang lebih baik pada ibu, sedangkan sectio caesarea memberikan luaran yang lebih baik pada bayi.

Tatalaksana antepartum penting dilakukan pada kehamilan kembar. Tujuan utama dari tatalaksanan antepartum kehamilan multijanin adalah menyediakan obeservasi maksimal terhadap ibu maupun janin guna mencegah komplikasi dari perkembangan, meliputi: gizi, surveilans antepartum dan pencegahan persalinan kurang bulan. $5,9,10$

\section{METODE PENELITIAN}

Penelitian ini dilaksanakan dengan metode retrospektif deskriptif yang bertujuan untuk melihat luaran persalinan gemeli di RSUP Prof. DR. R. D Kandou Periode 1 Januari 2014 - 31 Desember 2015. Subjek penelitian ialah semua pasien dengan riwayat persalinan kembar di Bagian Obstetri Ginekologi RSUP Prof. Dr. R. D. Kandou Manado periode 1 Januari 2014 - 31 Desember 2015 yang memiliki data rekam medik lengkap di BLU RSUP Prof. DR. R. D Kandou Manado

Variabel penelitian yaitu: Usia Ibu, Paritas Ibu, Presentasi Janin Intrauterin, Jenis Persalinan, Usia Kehamilan, Jenis Kelamin Bayi, Berat Lahir, APGAR Skor.

\section{HASIL PENELITIAN}

Total data persalinan gemeli periode 1 Januari 2014 - 31 Desember 2015 yang diambil untuk penelitian ini adalah sebanyak 60 kasus. Jumlah total persalinan periode 1 Januari 2014 - 31 Desember 2015 di RSUP Prof. Dr. R. D Kandou sebanyak 5038 persalinan, ini berarti kejadian persalinan gemeli di RSUP Prof. Dr. R. D Kandou hanya $0.012 \%$ dari jumlah total persalinan. Persalinan gemeli paling banyak ditemukan pada usia 21-25 tahun (28.3\%).

Tabel 1. Distribusi persalinan gemeli berdasarkan usia ibu

\begin{tabular}{lll}
\hline Usia & Frekuensi & \% \\
\hline$\leq 20$ & 11 & 18.3 \\
$21-25$ & 17 & 28.3 \\
$26-30$ & 14 & 23.3 \\
$31-35$ & 10 & 16.7 \\
$>35$ & 8 & 13.3 \\
Total & 60 & 100 \\
\hline
\end{tabular}

Kejadian persalinan gemeli berdasarkan paritas ibu paling banyak ialah kehamilan pertama (primipara) $(40.0 \%)$.

Tabel 2. Distribusi Persalinan Gemeli berdasarkan Paritas

\begin{tabular}{ccc}
\hline Partus & Frekuensi & \% \\
\hline 1 & 24 & 40.0 \\
2 & 22 & 36.7 \\
3 & 8 & 13.3 \\
4 & 2 & 3.3 \\
5 & 4 & 6.7 \\
Total & 60 & 100 \\
\hline
\end{tabular}

Presentasi bayi intrauterin tersering ialah presentasi letak kepala baik pada bayi $1(76.7 \%)$ maupun pada bayi $2(56.7 \%)$. 
Tabel 3. Distribusi Persalinan Gemeli dengan Presentasi Bayi Intrauterin

\begin{tabular}{lcccc}
\hline Presentasi & Bayi 1 & \% & Bayi 2 & \% \\
\hline Kepala & 46 & 76.7 & 34 & 56.7 \\
Sungsang & 14 & 23.3 & 19 & 31.7 \\
Lintang & 0 & 0.0 & 7 & 11.7 \\
Total & 60 & 100 & 60 & 100 \\
\hline
\end{tabular}

Metode persalinan yang terbanyak ialah spontan pervaginam baik untuk bayi 1 $(60.0 \%)$ dan $2(60.0 \%)$.

Tabel 4. Distribusi Metode Persalinan pada Persalinan Gemeli

\begin{tabular}{lcccc}
\hline $\begin{array}{l}\text { Jenis } \\
\text { Persalinan }\end{array}$ & $\begin{array}{c}\text { Bayi } \\
\mathbf{1}\end{array}$ & $\mathbf{\%}$ & $\begin{array}{c}\text { Bayi } \\
\mathbf{2}\end{array}$ & $\mathbf{\%}$ \\
\hline $\begin{array}{l}\text { Sectio } \\
\text { Caesarea }\end{array}$ & 24 & 40.0 & 24 & 40.0 \\
$\begin{array}{l}\text { Spontan } \\
\begin{array}{l}\text { Pervaginam } \\
\text { Total }\end{array}\end{array}$ & 36 & 60.0 & 36 & 60.0 \\
\hline
\end{tabular}

Usia kehamilan paling banyak adalah pada usia kehamilan 34-37 minggu (41.7\%).

Tabel 5. Distribusi Persalinan Gemeli dengan Usia Kehamilan Ibu

\begin{tabular}{ccc}
\hline $\begin{array}{c}\text { Usia Kehamilan } \\
\text { (minggu) }\end{array}$ & Frekuensi & \% \\
\hline$<30$ & 12 & 20.0 \\
$30-33$ & 3 & 5.0 \\
$34-37$ & 25 & 41.7 \\
$38-41$ & 20 & 33.3 \\
$>41$ & 0 & 0.0 \\
Total & 60 & 100.0 \\
\hline
\end{tabular}

Jenis kelamin bayi yang terbanyak ialah perempuan baik pada bayi $1(65.0 \%)$ maupun bayi $2(63.3 \%)$.

Tabel 6. Distribusi Persalinan Gemeli dengan Jenis Kelamin Bayi

\begin{tabular}{lcccc}
\hline Jenis & Bayi & $\mathbf{\%}$ & Bayi & \% \\
Kelamin & $\mathbf{1}$ & & $\mathbf{2}$ & \\
\hline L & 21 & 35.0 & 22 & 36.7 \\
P & 39 & 65.0 & 38 & 63.3 \\
Total & 60 & 100 & 60 & 100 \\
\hline
\end{tabular}

Berat badan lahir bayi 1 paling banyak ialah dari rentang berat 2000 sampai 2499 $(30.0 \%) \mathrm{g}$ dan untuk bayi 2 , berat badan lahir yang paling banyak adalah dari rentang berat 2500 sampai $2999 \mathrm{~g}(30.0 \%)$.

Tabel 7. Distribusi Berat Lahir Bayi 1 dan 2 pada Persalinan Gemeli

\begin{tabular}{|c|c|c|c|c|}
\hline Berat Lahir & $\begin{array}{c}\text { Bayi } \\
1\end{array}$ & $\%$ & $\begin{array}{c}\text { Bayi } \\
2\end{array}$ & $\%$ \\
\hline$<1000$ & 8 & 13.3 & 15 & 25.0 \\
\hline 1000-1499 & 4 & 6.7 & 1 & 1.7 \\
\hline 1500-1999 & 8 & 13.3 & 6 & 10.0 \\
\hline 2000-2499 & 18 & 30.0 & 15 & 25.0 \\
\hline 2500-2999 & 15 & 25.0 & 18 & 30.0 \\
\hline$>3000$ & 7 & 11.7 & 5 & 8.3 \\
\hline Total & 60 & 100 & 60 & 100 \\
\hline
\end{tabular}

APGAR score terbanyak ialah APGAR score 6-8 baik pada bayi 1 (30.0\%) dan 2 $(33.3 \%)$. Kejadian IUFD pada persalinan gemeli sebanyak empat kasus pada bayi 1 dan lima kasus untuk bayi 2 dan perinatal Death terjadi sebanyak satu kasus pada bayi 1 dan dua kasus pada bayi 2 .

Tabel 8. Distribusi APGAR Score pada Persalinan Gemeli

\begin{tabular}{ccccc}
\hline $\begin{array}{c}\text { APGAR } \\
\text { Score }\end{array}$ & $\begin{array}{c}\text { Bayi } \\
\mathbf{1}\end{array}$ & $\begin{array}{c}\text { \% } \\
\text { Bayi } \\
\mathbf{2}\end{array}$ & $\mathbf{\%}$ \\
\hline $0-1$ & 0 & 0.0 & 1 & 1.7 \\
$1-1$ & 3 & 5.0 & 3 & 5.0 \\
$1-3$ & 3 & 5.0 & 3 & 5.0 \\
$2-2$ & 1 & 1.7 & 0 & 0.0 \\
$3-3$ & 1 & 1.7 & 0 & 0.0 \\
$4-5$ & 0 & 0.0 & 1 & 1.7 \\
$4-6$ & 2 & 3.3 & 1 & 1.7 \\
$5-7$ & 9 & 15.0 & 8 & 13.3 \\
$6-8$ & 18 & 30.0 & 20 & 33.3 \\
$7-9$ & 17 & 28.3 & 15 & 25.0 \\
$8-10$ & 1 & 1.7 & 1 & 1.7 \\
IUFD & 4 & 6.7 & 5 & 8.3 \\
Death & 1 & 1.7 & 2 & 3.3 \\
Total & 60 & 100 & 60 & 100 \\
\hline
\end{tabular}

\section{BAHASAN}

Didapatkan 60 kasus dari 5038 kejadian persalinan, yang berarti persalinan gemeli hanya $0.012 \%$ dari seluruh persalinan. 
Pada Tabel 1, ditemukan bahwa kasus persalinan banyak terjadi pada ibu dengan rentang usia 21-25 tahun (28.3\%), bertentangan dengan teori yang menyebutkan bahwa semakin tingginya usia ibu merupakan salah satu faktor terjadinya kehamilan kembar. ${ }^{5,11}$ Walaupun menurut $\mathrm{Abel}^{12}$ faktor usia ibu hanya memberi sedikit efek.

Pada Tabel 2, ditemukan bahwa kasus persalinan gemeli terbanyak adalah pada primipara $(40.0 \%)$, bertentangan dengan teori bahwa kejadian kehamilan multijanin delapan kali lipat lebih mungkin pada ibu dengan paritas empat atau kurang dibandingkan dengan primipara. ${ }^{13}$

Pada Tabel 3, ditemukan bahwa kasus persalinan gemeli presentasi janin kembar yang paling banyak adalah presentasi kepala baik pada bayi 1 (76.7\%) maupun pada bayi 2 (56.7\%), disusul dengan presentasi sungsang (bokong) dan yang paling sedikit adalah presentasi lintang. Semua kombinasi presentasi pada kehamilan multijanin dapat terjadi, tetapi tiga kombinasi tersering adalah sefaliksefalik, sefalik-sungsang dan sefaliklintang. ${ }^{5}$

Pada Tabel 4, ditemukan bahwa kasus persalinan gemeli di terbanyak adalah terminasi dengan spontan pervaginam $(60.0 \%)$, sesuai dengan jumlah terbanyak presentasi janin yaitu presentasi kepala pada bayi 1 maupun bayi 2. Hal ini mengonfirmasikan teori yang mengatakan bahwa presentasi kepala-kepala pada persalinan kembar lebih baik dilakukan melalui spontan pervaginam. ${ }^{14,15}$

Pada Tabel 5, ditemukan bahwa kasus persalinan gemeli di terbanyak adalah pada rentang usia kehamilan 34-37 minggu $(41.7 \%)$. Angka ini mengikuti literatur yang mengatakan Kejadian prematuritas meningkat pada persalinan dengan gemeli, sekitar enam kali lipat persalinan gemeli ialah prematur dibanding dengan persalinan tunggal. ${ }^{16}$

Pada Tabel 6, ditemukan bahwa hasil persalinan gemeli terbanyak adalah bayi perempuan baik pada bayi 1 (65.0\%) maupun pada bayi 2 (63.3\%). Bayi perempuan hampir sepertiga dari jumlah keseleruhan bayi kembar. Hal ini dikarenakan janin perempuan lebih mampu bertahan dan juga zigot perempuan memiliki tendensi untuk membelah lebih besar. ${ }^{5}$

Pada Tabel 7, ditemukan bahwa luaran persalinan gemeli paling banyak adalah bayi dengan rentang berat badan antara 2000-2499 gram pada bayi 1 (30.0\%) dan rentang berat badan 2500-2999 gram pada bayi 2 (30.0\%). Bertambahnya jumlah janin, menurunkan angka berat badan pada masing-masing janin dikarenakan restriksi pertumbuhan fetal dan prematuritas. ${ }^{5}$ Belum ditemukan referensi yang menyatakan bahwa janin 1 atau 2 akan mengalami pertumbuhan yang lebih baik.

Pada Tabel 8, ditemukan bahwa luaran persalinan gemeli paling banyak adalah bayi dengan APGAR skor 6-8 baik pada bayi 1 (30.0\%) maupun pada bayi 2 (33.3\%). APGAR skor pada persalinan kembar sangat dipengaruhi usia ibu saat bersalin juga interval lahirnya bayi 1 dengan bayi $2 .{ }^{17}$

\section{SIMPULAN}

Dari hasil penelitian dan bahasan dapat disimpulkan bahwa dari faktor ibu yang terbanyak ialah usia ibu 21-25 tahun, dan paritas ibu persalinan pertama (primipara). Dari luaran persalinan, presentasi janin intrauterin terbanyak presentasi kepala baik pada bayi 1 maupun pada bayi 2, jenis persalinan spontan pervaginam baik pada bayi 1 maupun pada bayi 2, usia kehamilan ibu 34-37 minggu, Jenis kelamin persalinan bayi kembar yang paling banyak ialah perempuan baik pada bayi 1 maupun pada bayi 2, berat lahir terbanyak rentang 20002499 gram pada bayi 1 dan rentang 25002999 gram pada bayi 2, APGAR skor 6-8 baik untuk bayi 1 maupun untuk bayi 2 .

\section{DAFTAR PUSTAKA}

1. Prawirohardjo, Sarwono. Ilmu Kebidanan. Jakarta: Bina Pustaka Sarwono; 2009

2. Heard, Asha J. Multifetal Pregnancy [Internet]. MedScape References; 2016 [updated 2016 March 09; cited 
2016 August 23]. Available from: http://emedicine.medscape.com/articl e/1618038-overview

3. Angelina Tuange, Hermie M M Tendean, Freddy W Wagey. Profil Persalinan Kehamilan Kembar di BLU RSUP Prof. DR. R. D Kandou Manado Periode 01 Januari 2010 - 31 Desember 2011. PAAI Jurnal eBiomedik.2013;(1).

4. Irmi Lumempow, Juneke J Kaeng, Max R Raung. Karakteristik Persalinan Kembar di RSUD Prof R D Kandou Manado Tahun 2012 - 2013. PAAI Jurnal e-Biomedik. 2013;(3).

5. F. Gary Cunningham. William Obstetric. $24^{\text {th }}$ Ed. New York: McGraw-Hill Education;2014

6. ME, D'Alton. Delivery of the second twin. Obs Gyn J. 2010(115).

7. Barrett JFR, Hannah ME, Hutton EK. A randomized trial of planned cesarean. N Eng J Med. 2013;(369)

8. Yang Q, Wen SW, Chen Y. Occurrence and clinical predictors of operative delivery for the vertex second twin after normal vaginal delivery of the first twin. Am J Obs Gyn. 2005;(192).

9. Goodnight W, Newman R. Optimal nutrition for improved twin pregnancy. Obs Gyn J. 2009;(114)

10. Robinson BK, Miller RS, D'Alton ME. Effectiveness of timing strategies. Am J Obs Gyn. 2008;(207)

11. Beemsterboer SN, Homburg R, Gorter NA. The Paradox of declining fertility but increasing twinning rates with advancing maternal age. Oxford University

Press. 2006;1531(21):1460-2350.

12. Abel EL, Kruger ML. Maternal and paternal age and twinning in the United States. J Perinat Med. 2012;(40):2004-2008.

13. Olusanya BO, Solanke OA. Perinatal correlates of delayed childbearing in developing country. Arch Gynecol Obstet. 2012;(4).

14. Peaceman AM, Kuo L, Feinglass J. Infant morbidity and mortality associated with vaginal delivery in twin gestations. Am J Obstet Gynecol. 2009;(4)

15. Rossi AC, Mullin PM, Chmait RH. Neonatal outcomes of twins according to birth order, presentation and mode of delivery: a systematic review and meta-analysis. BJOG. 2011;(4).

16. Giuffre M, Piro E, Corsello G. Prematurity and twinning. The Journal of Maternal and Neonatal Medicine. 2012;(25).

17. Evrim ERDEMOGLU, Tamer MUNGAN, Omer L. TAPISIZ, Emin USTUNYURT and Ebru ÇAGLAR. Effect of inter-twin delivery time on Apgar scores of the second twin. Australian and New Zealand Journal of Obstetrics and Gynaecology. 2003;(43):203-206. 